\title{
La promoción de la vitivinicultura argentina: seis décadas, una función, múltiples actores
}

The promotion of Argentine viticulture: six decades, one role, multiple actors

Juan Jesús Hernández

Instituto Nacional de Tecnología Agropecuaria, Argentina

Universidad Nacional de San Juan, Argentina

juan.j.hernandez@inta.gob.ar

(iD https://orcid.org/0000-0003-0072-6461

\section{RESUMEN:}

El Estado argentino ha participado de múltiples maneras en la promoción de la vitivinicultura argentina, entendida tanto como políticas de apoyo a la innovación, la competitividad y la inversión, como intervención en los mercados para sostener precios remunerativos para algunos de sus actores, según la extensión del concepto adoptado por la Ley General de Vinos 14.878 / 1959. El presente artículo estudia cómo se implementó la promoción de esta agroindustria desde el Estado a partir de la sanción de esa ley hasta la actualidad, identificando qué organizaciones asumieron tareas que intentarían generar beneficios para un conjunto de agentes, aunque también podrían perjudicar a otros y por lo tanto ser cuestionadas por ellos. La definición y la extensión del concepto y la distribución de tareas entre organizaciones estatales o mixtas generaron disputas a lo largo de las décadas. La metodología es cualitativa y se centra en el análisis de bibliografía especializada y de entrevistas a actores claves.

Palabras ClaVe: Vitivinicultura, Promoción, Organizaciones, Estado.

\begin{abstract}
:
The Argentine State has participated in multiple ways in the promotion of Argentine viticulture understood both as policies to support innovation, competitiveness and investment, as well as intervention in the markets to sustain remunerative prices for some of its actors, according to the extent of the concept adopted by the General Law of Wines 14.878 / 1959.

This article studies how the promotion of this agribusiness was implemented by the State from the enactment of that law to the present, identifying which organizations assumed tasks that would try to generate benefits for a group of agents, although they could also harm others and therefore be questioned by them. The definition and extension of the concept and the distribution of tasks among state or mixed organizations generated disputes over the decades. The methodology is qualitative and focuses on the analysis of specialized bibliography and interviews with key stakeholders.
\end{abstract}

KEYWORDS: Viticulture, Promotion, Organizations, State.

\section{INTRODUCCIÓN}

En Argentina, la vitivinicultura tiene una fuerte presencia territorial en Mendoza y San Juan por factores productivos, históricos y culturales. A pesar de los procesos de concentración de la propiedad de la tierra y de las bodegas registrados en las últimas décadas, es una agroindustria con un número amplio de actores en los diversos eslabones de sus cadenas productivas. Desde los orígenes coloniales de la actividad, su desarrollo estuvo ligado tanto a la iniciativa empresaria individual como a las acciones de organizaciones de la sociedad civil y del Estado en sus diferentes niveles u organizaciones. Su promoción no dependió exclusiva ni principalmente de las empresas individuales o de sus cámaras.

El presente artículo estudia cómo se implementó la promoción de la agroindustria desde el Estado a partir de 1959 en que sancionó la Ley General de Vinos 14.878, hasta la actualidad, identificando qué organizaciones 
asumieron tareas que intentarían generar beneficios para un conjunto de agentes, aunque también podrían perjudicar a otros y por lo tanto ser cuestionadas por ellos, ya que las políticas públicas no son neutrales en términos de distribución de recursos.

El trabajo parte de los problemas estructurales de las cadenas productivas de esta agroindustria que llevaron a que algunos agentes demandaran que el Estado interviniera, adoptando un concepto amplio de promoción, que incluía no sólo el despliegue o crecimiento de las fuerzas productivas sino también el sostenimiento de precios remunerativos para los pequeños productores.

Tal función, entendida de esas dos maneras, se concentró en el Instituto Nacional de Vitivinicultura hasta la década de 1990 en la que el concepto se disoció entre sus dos vertientes, dejando la búsqueda de equilibrios en los mercados para evitar crisis de sobrestock de vinos en los gobiernos provinciales y las tareas de promoción de la innovación tecnológica, el incremento de la calidad de los productos y la mejora de su competitividad para la exportación en el ámbito tanto de esos gobiernos como de nuevas entidades que surgieron en estos años, especialmente el Fondo Vitivinícola de Mendoza (FVM) y la Corporación Vitivinícola Argentina (COVIAR).

La dispersión de la responsabilidad no se dio mediante una planificación coordinada, sino fruto de un proceso histórico en el que las estrategias de los diferentes agentes influyeron, y que ha dejado abierta la posibilidad a la superposición de tareas entre las organizaciones que se analiza en el penúltimo apartado.

El marco teórico está basado en algunos elementos del Enfoque Estratégico Relacional de Robert Jessop. La metodología es cualitativa y se centra en el análisis de bibliografía especializada y de entrevistas a actores claves. $^{1}$

El trabajo demuestra que el poder de la promoción, entendido como regulación de los mercados de la vitivinicultura y como apoyo al desarrollo o la competitividad de los agentes, lo han asumido principalmente organizaciones estatales, con o sin participación de agentes del sector privado en su conducción, ya que demanda inversiones importantes y genera externalidades positivas para un conjunto actores, a la vez que las decisiones que se toman en su ejercicio implican una redistribución de recursos o una orientación del desarrollo que puede perjudicar a otros. De manera que no pueden ser solo asumida por actores individuales, que se suelen concentrar en la publicidad de sus propios productos. Existen condiciones propias de una agroindustria con múltiples participantes, que llevan a la necesidad de regulación de los mercados y de la existencia de espacios de concertación para el funcionamiento de un complejo andamiaje institucional que necesita coordinar y acordar objetivos comunes.

Este artículo pretende contribuir a la bibliografía especializada sobre la vitivinicultura nacional ${ }^{2}$, que desde diferentes marcos teóricos, periodos e instituciones, ha propuesto formas de comprender la participación del Estado en esta agroindustria.

\section{Algunos elementos Del EnfoQue estratégico relacional (EER) De Robert Jessop}

Para Jessop (2008) el Estado se articula en torno a la toma de decisiones vinculantes para una comunidad política. Su unidad no es monolítica ni completa, sino que es más bien un conjunto relativamente unificado de instituciones, organizaciones, fuerzas sociales y actividades.

Esta concepción rechaza la imagen de un organigrama burocrático tradicional para pensar un Estado cuyos límites imprecisos se van modificando con el tiempo fruto de la correlación de fuerzas sociales. Las funciones que se le confieren a las organizaciones estatales cambian y se expresan en decisiones que impactan en los agentes sociales que despliegan estrategias para que ellas los favorezcan.

Las fuerzas políticas tienen diferente poder o capacidades disímiles para lograr el acceso o dominio (directo o indirecto) al aparato estatal (Jessop, 2014). De esta manera, las decisiones del Estado no son neutrales en cuanto a distribución de recursos, no solo por sus resultados finales, sino también por su intencionalidad previa que puede estar destinada a favorecer a determinadas fuerzas sociales, grupos u organizaciones. 
Para el autor, por encima, alrededor y debajo del núcleo del Estado se encuentran instituciones y organizaciones relacionadas con ese núcleo, de tal modo que vuelven problemática la integración efectiva del Estado como un conjunto institucional que persigue políticas coherentes. Las fronteras del Estado tienen una geometría variable que se rediseña.

La naturaleza de las instituciones estatales y sus articulaciones entre sí y con otros órdenes de la sociedad dependen de las características de la formación social y de su historia. Lo que se identifica como "interés común" o "voluntad general", y sirve como argumento de las intervenciones estatales, es ilusorio en tanto su definición ocurre en un terreno estratégicamente selectivo e implica una articulación y agregación diferencial de opiniones y valores (Jessop, 2014; Hernández y Doncel Ramallo, 2020). Lo que aparenta ser en beneficio de un interés general, beneficia a unos y perjudica a otros.

Sostiene Jessop (2008) que en el siglo XXI no hay una extinción del Estado nacional, sino una erosión de su poder. Pierde peso relativo la coacción centralizada en las distintas políticas del Estado y adquieren protagonismo nuevos sistemas de colaboración con actores privados, paraestatales y no gubernamentales. A su vez se registra un aumento de la importancia del ámbito subnacional y del internacional (Valenzuela Espinoza, 2014).

En este sentido, en las últimas décadas, han surgido organizaciones que, aunque tienen poder o funciones concedidas por el Estado, cuentan con participación privada (minoritaria o mayoritaria) en su conducción. La tarea de estas entidades "mixtas" es crear políticas públicas que tengan una mejor "apariencia de voluntad general”, al tomar las decisiones fruto del debate entre los actores involucrados, más allá que en los procesos políticos y en el mercado, unos tengan mayor poder que otros. Se trata de espacios de concertación:

Los espacios de concertación se definen como ámbitos de negociación, diálogo y participación en los que los grupos involucrados toman posición frente a los temas de agenda, realizan acuerdos y compromisos explícitos o tácitos e intentan influir sobre las políticas públicas. En ellos los individuos tienen alianzas, consensos, conflictos y tensiones con otros agentes privados y estatales, y no todos los miembros tienen las mismas capacidades en el ejercicio del poder. El Estado se considera como un actor más, que sólo en ocasiones convoca o lidera, pero siempre conserva el privilegio del monopolio de la coerción (Moscheni \& Hernández, 2020, p. 305).

En este trabajo se analiza cómo una función asumida por el Estado fue redefinada con el tiempo y cómo fue cambiando la/s organización/es que la tomó/aron a su cargo en distintos contextos históricos. En especial las tareas vinculadas a la promoción de la vitivinicultura tendieron a estar localizadas en organizaciones que constituyen espacios de concertación porque la definición de las decisiones aparentarían mejor responder al interés común, en la medida que en ellas participan varios actores, de manera que se encubren en parte las relaciones desiguales de poder y los conflictos.

\section{Algunos aspectos estruCturales De la VitiVinicultura ARgentina}

Debido a las condiciones climáticas y a los factores históricos y culturales, las provincias con mayor superficie cultivada con vid son Mendoza, donde se han localizado en las últimas 6 décadas aproximadamente el 70 \%de las hectáreas, y San Juan, con alrededor del 20 \% de las mismas. El resto de la producción se distribuye entre La Rioja, Río Negro, Catamarca, Salta, Neuquén y otras.

En Argentina el destino mayoritario de la uva es la vinificación (elaboración de vinos principalmente y fabricación de mostos), registrando volúmenes inferiores en la producción de pasas y el destino a consumo en fresco.

La elaboración de vinos tuvo durante el siglo XX crisis transitorias de sobreproducción de uva y de vino de traslado que se generaron por problemas estructurales de la cadena productiva. Estas crisis han sido frecuentes y cíclicas, motivadas por desfasajes en la oferta en años en que el clima permitió buenos rendimientos o donde las inversiones en nuevas plantaciones no tuvieron en cuenta procesos de contracción de la demanda, como 
ocurrió en la crisis de la década de 1980 motorizada por el descenso en el consumo de vinos en el mercado interno. $^{3}$

Los grandes bodegueros con capacidad de fraccionamiento están en mejores condiciones para negociar precios y condiciones de pago en las cadenas productivas, y pueden beneficiarase de las economías de escala. La tendencia en los últimos 60 años ha sido al surgimiento de oligopolios en la demanda de vino de traslado para fraccionamiento (Hernández, 2014b; 2020).

Los desequilibrios estructurales de la vitivinicultura se han demostrado difíciles de enfrentar por el grado de especialización que suelen tener los productores y por las connotaciones sociales y económicas que tiene la actividad en algunas provincias. Por ello ante estas crisis algunos sectores suelen pedir la intervención del Estado para que evite, corrija o solucione sus causas y/o efectos (Díaz Araujo \& Iuvaro, 2006). ${ }^{4}$

A este panorama, en los últimos años se ha sumado el incremento de la importancia de la logística y comercialización, a través de grandes cadenas de supermercados, especialmente en el segmento de vinos comunes para el mercado interno. Esto ha agregado un actor clave a la cadena productiva para el cual los productos vitivinícolas son tan solo uno de los tantos que comercializa. Al oligopsonio en el mercado de la uva y del vino de traslado, se ha agregado el oligopsonio de la demanda de vinos fraccionados listos para la venta al consumidor.

En 2019, en Argentina existían 215.169 hectáreas cultivadas con vid, distribuidas en 23.668 viñedos, de los cuales el 77,7 \% tienen menos de 10 hectáreas. Las bodegas elaboradororas fueron 883 . Todos estos indicadores demostraron un retroceso con respecto a 2010. En cambio, en el mismo periodo aumentaron las exportaciones de vinos en un 13,8 \% (COVIAR, 2020). A pesar ello, al mercado interno se continuó destinando más del $70 \%$ de la producción vínica. Esta característica de la agroindustria la mantiene depediente en buena parte de la economía nacional, y de sus crisis, a la vez que las dinámicas exportadoras generan la tendencia creciente a la adaptación a pautas internacionales de producción y consumo. Agrega además otro problema estructural que es la divergencia de intereses entre los productores y elaboradores de vinos orientados a uno u otro mercado, cuyos intereses difieren en cuanto a su posición con respecto a las políticas de apertura al comercio exterior, por ejemplo. A la vez que existen otros que logran segmentar su producción para participar de diferentes mercados.

La vitivinicultura nacional se caracteriza por la existencia de un número considerable de actores. Estos a su vez han conformado organizaciones representativas de los diferentes sectores de las cadenas productivas que articulan entre sí, con el gobierno nacional y con los gobiernos provinciales y municipales. De esta manera se configura un complejo entramado institucional caracterizado por relaciones de cooperación y conflicto. En él, las entidades de bodegueros adquieren un papel relevante por la posición de sus representados en las cadenas productivas y por su capacidad de movilización de recursos (económicos, políticos, comunicacionales, etc.).

El gobierno nacional, principalmente a través del Ministerio de Agricultura, Ganadería y Pesca, diseña políticas. Dentro de este ministerio, el Instituto Nacional de Vitivinicultura (INV) es el que tiene injerencia específica en esta agroindustria, pero también contribuyen otros que no son exclusivos para la vitivinicultura, como el Instituto Nacional de Tecnología Agropecuaria (INTA) o el Servicio Nacional de Sanidad y Calidad Agroalimentaria (SENASA). Los gobiernos de las provincias de mayor producción vitivinícola del país también cuentan con agencias o departamentos estatales involucrados en temas vitivinícolas. Entre ellos se destaca el Fondo Vitivinícola de Mendoza (FVM), creado tras el convenio interprovincial de diversificación hacia mostos de mediados de la década de 1990, con tareas de promoción del consumo, entre otras.

La diversidad de organizaciones representativas de productores e industriales brinda oportunidades para la participación, pero a la vez complejiza las vinculaciones dentro del sector, lo cual hace necesaria la existencia de espacios de concertación. Su composición es diversa, participando organizaciones del sector privado, consejos profesionales, organismos de ciencia y técnica, entre otros. El principal de ellos es la Corporación Vitivinícola Argentina (COVIAR) que se encarga de la gestión del Plan Estratégico Vitivinícola (COVIAR, 
2020; Moscheni \& Hernández, 2020). Las funciones de cada uno han sido variables a lo largo de la historia, brindando la posibilidad para la interacción, cooperación y superposición de intereses y acciones.

El objetivo de este trabajo es analizar cómo la función de promoción, concepto definido de diferentes formas en distintos contextos históricos, fue asumida por cada una de estas organizaciones desde 1959 hasta la actualidad.

La diversidad de actores, muchos de capitales pequeños y medianos, y la importancia social y económica de la actividad para las provincias cuyanas, motivaron que esta función no pudiera quedar simplemente en la responsabilidad de cada actor individual, a pesar de que ellos son los que se beneficiarían en última instancia. Incluso la inserción de los productos argentinos en los mercados internacionales estuvo motorizada desde entes estatales principalmente, o desde entidades del sector privado como Wines of Argentina (Wofa), que es en parte financiada por COVIAR. Los actores de mayor importancia tampoco pudieron por sí solos lograr el acceso a mercados exigentes. La publicidad individual que las grandes empresas pueden hacer en el país o en el extranjero se ha relevado insuficiente cuando no está acompañada de misiones y acuerdos comerciales generales, difusión de las bondades para la salud del consumo de vinos, grandes campañas de promoción donde no se pone foco en una marca sino en el valor social y cultural del consumo, programas de investigación para la resolución de problemas tecnológicos comunes, etc. En un mercado mundial de altísima competencia, las estrategias de las empresas de los países han tendido a ser concertadas entre sí, tal como lo demuestra la proliferación de planes estratégicos nacionales en el siglo XXI. ${ }^{5}$ Del mismo modo en el mercado interno: las acciones de promoción no quedaron en la iniciativa individual. Un ejemplo de esto último puede ser la instalación mundial del reconocimiento de la calidad del malbec argentino, que beneficia a todos los productores.

Es decir, organizaciones estatales con o sin participación privada asumieron las tareas y el gasto que demandaban acciones con externalidad positivas que en última instancia serían apropiadas por actores del sector privado, cuyos intereses estaban en juego.

\section{LA FUnCión de Promoción En EL Instituto Nacional de Vitivinicultura}

El INV surgió en 1959, mediante la "Ley General de Vinos" N. ${ }^{\circ}$ 14.878, como respuesta al problema del fraude en la elaboración de vinos registrado en los años anteriores.

La adulteración más frecuente era el estiramiento del vino con agua. También era usual encabezarlos, esto es, incorporar alcohol vínico, procedimiento permitido por la ley cuando el caldo tenía baja graduación natural, pero que se utilizaba como paso previo al aguamiento. Por otra parte, era común que los vinos que quedaban de la cosecha anterior, casi siempre avinagrados, fueran mezclados con los nuevos caldos. El añadido de ciertas drogas (no permitidas por la ley) a los vinos mal elaborados era otra costumbre de los bodegueros - falsificadores.... Además, era habitual hacer pasar por vino a bebidas artificiales que imitaban ese sabor (Barrio, 2008, p. 86).

La ley 14.878/1959 fue creada sobre la base de otras normativas anteriores, ${ }^{6}$ especificó las normas técnicas para el control de la genuinidad de los productos vitivinícolas, estableció sanciones a los infractores y creó al INV como organismo autónomo y autárquico dentro de la estructura del Estado nacional, con una conducción que intentó condensar en su interior la representación de los diversos sectores de la agroindustria vitivinícola (AIV) e institucionalizar sus conflictos en un espacio de concertación.

Según el artículo 2 de la ley, el Instituto fue dotado de dos funciones: control técnico de la producción y promoción de la agroindustria. La primera se refiere al dictado de normas, la realización de procedimientos y la aplicación de sanciones para garantizar la genuinidad de los productos vitivinícolas. La segunda es más amplia, y se interpretó que se refería como mínimo a acciones de investigación, asesoría a otros organismos, fomento de nuevas tecnologías, capacitaciones, difusión, registros de producción y viñedos y elaboración de estadísticas (Díaz Araujo \& Iuvaro, 2006). 
La falta de definición precisa del término promoción llevó a que fuera comprendido de dos maneras:

- Facultad para promover o incentivar el consumo y la producción vitivinícola.

- Poder para regular la oferta en los mercados.

La extensión del concepto fue fuente de enfrentamientos jurídicos y políticos entre los actores en los años posteriores.

El “Instituto del Vino", como se le decía entonces, no solo buscaría el desarrollo general de la agroindustria en cuanto a competitividad, calidad, etc., sino que también podría influir en los mercados para sostener a algunos actores particulares; en especial a los productores de uva ante las frecuentes crisis de sobrestock.

El artículo 4 de la ley establecía que el Instituto sería conducido por un presidente designado por el Poder Ejecutivo Nacional, que tendría funciones ejecutivas, pero solo tomaría decisiones en caso de empate en el Consejo Directivo, conformado por representantes de gobiernos provinciales ( 2 de Mendoza, 2 de San Juan, 1 de Río Negro, 1 de La Rioja y 1 de la siguiente provincia en orden de volumen de producción) y de organizaciones del sector privado ( 1 de cada una de las que tenían mayor número de afiliados de obreros, productores de uva, industriales, cooperativas vitivinícolas y fraccionadores).

La forma colegiada de conducción del Instituto fue un modelo de distribución de poder en la agroindustria y un auténtico espacio de concertación con la potestad de decidir en nombre del Estado. El Consejo Directivo solo estuvo en funciones entre 1959 y 1963, 1966-1968 y 1984-1989. Mientras que entre 1963-1966, 1968-1984 y 1990-1991 fue intervenido por el gobierno nacional, que suspendió la representación de los gobiernos provinciales y del sector privado, concentrando todo el poder de decisión en la figura del interventor.

La misma ley estableció el modo de financiamiento del INV, que se realizaría principalmente mediante un impuesto, o sobretasa, del $3 \%$ sobre la base imponible del vino expendido, además de ingresos por tasas por análisis obligatorios que deben pagar las empresas, las multas que se aplicarían por transgresiones a las disposiciones de la ley, las partidas que le asigne el Poder Ejecutivo de rentas generales, venta eventual de productos, donaciones y legados.

Los restantes artículos de la ley contenían normas de carácter técnico que especifican modos de análisis, clasificación de los distintos tipos de vinos y otros productos derivados de la uva, prácticas lícitas y prohibidas en la agroindustria y sanciones que el INV podría aplicar en caso de infracciones (Hernández, 2014a, 2017a y 2020).

El control de la calidad de los productos fue el principal objetivo de la ley. Pero Castiñeira de Dios (1999) aclara que las sanciones contra la adulteración no solo buscaron proteger la salud del consumidor sino también preservar a la industria en general de su desprestigio.

Cada una de las atribuciones y tareas que asumió el INV tendría carácter no solo técnico ya que su aplicación tendría como consecuencias efectos económicos generales y sobre agentes concretos. Por ejemplo, el pronóstico de cosecha que realiza este Instituto es tenido en cuenta por los actores para la definición de precios de la uva en cada vendimia, o la fecha de liberación de los nuevos vinos que se fija puede ser adelantada o atrasada para regular stocks en los mercados. Es decir, también puede ser utilizada para sostener precios en beneficios de algunos agentes (Hernández, 2014a y 2020).

Entonces, desde su creación y hasta 1991, el Instituto ejerció sus funciones de fiscalización y de promoción, entendiendo esta última de dos maneras. Por un lado, como promoción del crecimiento cuantitativo y cualitativo de la agroindustria por el aumento de la superficie cultivada (se puede mencionar, por ejemplo, el incentivo a nuevas plantaciones en las décadas de 1960 y 1970), integración en las cadenas productivas (apoyo económico al surgimiento de bodegas estatales en San Juan y Mendoza para que los viñateros muelan sus uvas en la década de 1970, o apoyo al fraccionamiento en origen con el diseño o implementación de las normas de 1963 y 1984), fomento de la diversificación de destinos de la uva y de mercados para el vino (por ejemplo, en las dos gestiones del interventor Aniceto Pérez de las décadas de 1960 y 1970, que planteaban enunciados 
programáticos en torno a la producción de pasas y mostos y el incentivo a la exportación como salida a los excedentes), etc. Pero, por otro lado, el concepto promoción fue entendido también como establecimiento de normas que regulaban la oferta a través de bloqueos de vinos de traslado, cupos de uva que podrían ser destinadas a la vinificación, prorrateos de salida de vinos para el consumo, etc. Estas acciones se sucedieron año tras año e intentaron atender la crisis de superproducción generadas por los problemas estructurales de la cadena productiva (desfasajes entre oferta y demanda), potenciados por la reducción del consumo interno registrado desde la década de 1980. Las medidas regulatorias fueron tomadas con la intención de sostener precios de la uva y del vino de traslado en beneficio de productores de uva y bodegueros, pero cuando eran dejadas de lado se favorecía a las empresas fraccionadoras - envasadores-. La tensión entre estos actores marcó el devenir del Instituto y sus cambios de autoridades en sus primeras 3 décadas de existencia.

La cantidad comercializada en una economía de mercado libre se fija por la relación entre oferta y demanda; en cambio en la vitivinicultura entre las décadas de 1960 y 1990 fue sumamente influida por las decisiones tomadas en el INV. Ello se puede entender en el marco de un Estado con una amplia intervención a nivel nacional en múltiples áreas de la vida social y económica.

Esta situación cambió cuando asumió la presidencia de la Nación Carlos Menem. La ideología neoliberal de la que participaba sostenía la necesidad de desregular los mercados, limitar el tamaño de las instituciones estatales y dar mayor libertad de acción a los agentes privados. El discurso hegemónico proclamaba que el libre juego del mercado contribuiría al desarrollo y que la función estatal sería crear las mejores condiciones para el crecimiento de las empresas sin condicionar su actividad mediante políticas coercitivas. Por ello se entiende que ahora la promoción asumida por el Estado nacional fuera entendida solo en el primer sentido, es decir en cuanto incentivo de la competitividad privada, y no en la segunda acepción, referida a la intervención para equilibrar mercados o sostener a los agentes más débiles en las negociaciones propias de las cadenas productivas.

El decreto "de Desregulación Económica" N. 2.284 de 1991 redujo la estructura del INV eliminando el Directorio (el espacio de concertación), y le quitó su función de promoción de los mercados y sus instrumentos. Le quedó solamente su rol de fiscalización o control de calidad. Además, abolió la sobretasa al vino y con ello la financiación específica para el Instituto, que pasó a depender de las partidas asignadas por el presupuesto nacional.

Paralelamente, en la vitivinicultura argentina comenzó una paulatina reconfiguración de actores por los procesos de aumento de la diversificación de productos (mostos, vinos finos, uva de mesa, pasas) y mercados (permanencia de un importante mercado interno en contracción y apertura de mercados externos), por la expulsión de productores primarios e industriales pequeños y medianos, por la llegada de inversiones nacionales y extranjeras y por la adaptación a las pautas internacionales de elaboración. Las empresas que pudieron adaptarse a las nuevas condiciones llevaron adelante una reconversión con el cultivo de variedades de uvas finas, la incorporación de nuevas tecnologías en viñedos y bodegas, la exportación, la diferenciación de productos y el aprovechamiento de actividad vinculadas como la gastronomía o el turismo (Hernández, $2014 b, 2014 a$ y 2020). Así se dejó de lado las políticas de reducción y control de la oferta, para pasar a políticas de liberación de mercados y de impulso de la producción de vinos finos para la exportación.

Sin embargo, las funciones regulatorias del INV no fueron abandonadas. Las autorizaciones para las importaciones o para el traslado interprovincial de vinos para cortes, el desbloqueo de los caldos en poder del Estado desde la década anterior, etc., beneficiaron a los grandes bodegueros porque generaron tendencias a la contracción del precio de la uva.

La eliminación de la sobretasa al vino obligó a que el Instituto dependiera de fondos asignados en el presupuesto del Estado nacional y susceptibles al ajuste. De pasar de ser solventado por el mismo sector, pasó a ser un "peso" a las arcas públicas para la ideología neoliberal que propiciaba el achicamiento del Estado. El presupuesto del Instituto se redujo de 43 millones a poco más de 12 millones entre 1989 y 2001 (Hernández, $2020)$. 
En 2003, el Decreto 1279 explicitó y actualizó los objetivos del Instituto que pusieron de manifiesto sus funciones que se mantienen hasta la actualidad. Ellos son:

- Aprobar y coordinar la ejecución de planes y programas para el control de la genuinidad y aptitud para el consumo de los productos vitivinícolas, en las etapas de producción, elaboración, fraccionamiento y comercialización, de acuerdo con lo dispuesto por la Ley N. ${ }^{\circ} 14.878$ y normas modificatorias y complementarias.

- Aprobar y coordinar la ejecución de planes y programas para ejercer el control de la producción, circulación, fraccionamiento y comercialización de alcoholes, conforme a lo normado por la Ley Nacional de Alcoholes N. ${ }^{\circ} 24.566$.

- Promover investigaciones sobre los productos vitivinícolas y los alcoholes para lograr la permanente actualización de los mecanismos de control.

- Participar en reuniones de organismos técnicos internacionales vinculados al sector vitivinícola y alcoholes.

- Entender en las certificaciones correspondientes a las exportaciones, contribuyendo a la adopción de medidas destinadas a facilitar el comercio internacional de los productos de su competencia.

- Adoptar un sistema de aseguramiento de la calidad en base a normas internacionalmente reconocidas.

- Entender en la ejecución de las normas que hacen a la designación del origen de vinos y bebidas espirituosas de naturaleza vínica, conforme a la Ley N. ${ }^{\circ} 25.163$.

- Coordinar y realizar en su carácter de organismo específico la actualización permanente de las estadísticas vitivinícolas y de alcoholes.

- Poner en vigencia las disposiciones que en materia vitivinícola se adopten en el Mercado Común del Sur (MERCOSUR), interviniendo en la armonización de las normas técnicas del control.

- Integrar como órgano técnico específico en materia vitivinícola y de alcoholes los sistemas y cuerpos de la Secretaria de Agricultura, Ganadería, Pesca y Alimentos del Ministerio de la Producción, a fin de lograr una actuación coordinada en el ámbito de la actividad vitivinícola y de alcoholes.

- Asistir a organismos nacionales y provinciales en los temas de su competen (Decreto del Poder Ejecutivo Nacional de la República Argentina No 1279/2003).

El primer objetivo expresaba la principal función del Instituto: la fiscalización o contralor técnico vitivinícola. Los demás mencionan las restantes: la investigación en materia enológica y de alcoholes en general, certificación de calidad fundamental para la venta interna y la exportación, la obtención y publicación de estadísticas para la vitivinicultura, la representación ante organismos internacionales, la colaboración con organizaciones estatales y la aplicación de las leyes de alcoholes y de denominaciones en origen. Aquí el concepto de promoción de la antigua de la ley 14.878/1959 subsiste en parte, pero no en el sentido de regulación de mercados, sino en el de apoyo al desarrollo.

En el nuevo siglo con el fortalecimiento del rol del Estado tras el cambio en la orientación de la política económica nacional, el Instituto tuvo más personal y recursos para los controles de calidad, pero no retomó su rol regulador de la oferta, aunque sus acciones aparentemente técnicas como los pronósticos de cosecha, definición de grados alcohólicos mínimos, fecha de liberación de nuevos vinos, entre otras, tengan efectos económicos sobre los actores. ${ }^{7}$

\section{LA FUnCión DE PROMOCión EN LOS GOBIERNOS PROVINCIALES Y EN EL Fondo Vitivinícola de Mendoza}

Los gobiernos provinciales tienen una amplia trayectoria de promoción de la vitivinicultura en Argentina, en las dos acepciones del concepto acuñado por la ley 14.878/1959. Los antecedentes a rastrear pueden ser 
muy antiguos. Para los años que abarca este trabajo, se pueden mencionar en primer lugar la compra de Bodegas Giol por el Estado mendocino y la creación de CAVIC por el Estado sanjuanino. Ellas fueron en cierto sentido acciones de promoción, entendida como intentos de regular el mercado, mediante la incorporación de nuevos actores que compraban uva y vino de traslado a mejores precios que las empresas privadas competidoras. ${ }^{8}$

Durante la década de 1980, cuando el consumo interno se redujo y los sobrestocks presionaban a la baja de los precios, también aparecieron políticas provinciales de apoyo a la diversificación hacia la producción de mostos, pasas y uva de mesa, el recambio de varietales, la compra de excedentes para destinarlos a la destilación o a la exportación, etc. Aquí el concepto de promoción se expresó en el sentido de apoyo al desarrollo de la actividad para que no se concentrara exclusivamente en la elaboración de vinos comunes destinados al mercado interno. También se ensayaron políticas de control de la oferta mediante prorrateos a la salida de vinos en Mendoza, por ejemplo (Hernández, 2020) que estuvieron escasa vigencia por las presiones de los agentes y por los reclamos de liberación de mercados que tomaban fuerza en esos años.

La ideología neoliberal que inspiró las políticas del gobierno nacional en la década de 1990 penetró en menor profundidad en los gobiernos provinciales, más proclives a recibir las presiones de productores y elaboradores cuyanos que reclamaban la intervención del Estado frente a las asimetrías que generaba el libre mercado (Ferreyra, 2010). Así se llegó a la reedición regional de políticas de control de la oferta, en un contexto de caída del consumo interno de vinos.

Los gobiernos de San Juan y Mendoza fueron quienes asumieron por lo menos una parte de la capacidad de regulación que el Estado nacional cedió. La principal de sus acciones fue la política conjunta de direccionamiento de excedentes a la producción de mostos que se aplicó desde 1995. El objetivo principal fue controlar los stocks de vinos, para evitar las crisis de superproducción; por ello, el porcentaje anual definido varía en función de los cálculos de cosecha del INV, de la previsión de la demanda externa y de exportación y de las presiones de las cámaras (las organizaciones de viñateros suelen solicitar que se destinen mayores volúmenes a mostos porque eso hace que la uva para vino valga más, mientras que las organizaciones bodegueras tienen intereses contrarios). Se establecen sanciones para quienes incumplan, tales como un monto en dinero por kilo de uva que se destine a vino por encima del cupo.

El tratado previó el origen de un Fondo Vitivinícola en cada una de las provincias, con el carácter de persona jurídica de derecho público no estatal, al que aportarían las bodegas que no cumplieran con el porcentaje fijado para mostos, a lo que se adicionaría un aporte estatal en concepto de reintegro por las demás cargas que graban a la industria. El objetivo era utilizar esos fondos para incentivar la elaboración de jugo de uva, aumentar el consumo interno y las exportaciones, y con ello también disminuir excedentes del mercado de vinos y elevar los precios (Hernández, 2020).

En San Juan nunca se constituyó ese Fondo porque en general se cumplieron los porcentajes anuales de diversificación. En cambio, en Mendoza se integró por organizaciones de empresarios y el gobierno provincial. El FVM asumió parte de la antigua función de promoción que tenía el INV, entendida solo como apoyo al crecimiento de la actividad y no como intervención en los mercados.

El Fondo tiene como misión promover el consumo de vinos en Argentina, la difusión de su cultura y el crecimiento integral de la actividad, a través de estrategias y acciones de comunicación (Bertranou, 2011).

Según su ley de origen, de la conducción del FVM participan: Asociación de Cooperativas Vitivinícolas; Asociación de Viñateros de Mendoza; Cámara Argentina de Fabricantes y Exportadores de Mosto; Cámara de Agricultura, Industria, Comercio y Ganadería del Valle de Tupungato; Cámara de Comercio, Industria y Agricultura de Tunuyán; Cámara de Comercio Industria y Agropecuaria de San Rafael; Cámara de Comercio, Industria, Agricultura y Ganadería de General Alvear; Cámara Empresaria de Rivadavia; Gobierno de Mendoza; y Unión Vitivinícola Argentina (UVA). La forma de conducción de su directorio hace que sea un auténtico espacio de concertación. 
El FVM fue dominado desde sus orígenes por la UVA, que propició que se dedicara a la promoción genérica del vino. Esto provocó la salida del ente del Centro de Bodegueros de Mendoza (hoy Bodegas de Argentina), que quería que se atendiera principalmente la promoción del vino fino y la exportación, negocio en el que se especializan sus principales bodegas afiliadas (que son las más grandes del país). El conflicto demostró nuevamente que la promoción aún en su faz "no intervencionista en los mercados" no es neutral en cuanto a distribución de recursos y orientación de modelos de desarrollo. El destino de los recursos a uno u otro fin es objeto de disputa entre los agentes.

\section{La Corporación Vitivinícola Argentina (COVIAR)}

El surgimiento de la COVIAR reeditó un mecanismo de participación amplio de los actores de la vitivinicultura a nivel del país, como ocurría en el antiguo Consejo Directivo del INV.

La COVIAR asumió la antigua función de promoción que tuvo el INV, pero sin la potestad ni la intención de regular o influir en la oferta de vinos para garantizar precios. El epicentro de las estrategias de los actores para defender sus intereses en el siglo XXI se localiza en esta entidad y en la definición de políticas de los gobiernos provinciales (en especial el cupo obligatorio que debe destinarse anualmente a mostos).

El Estado argentino tuvo un rol activo en el nuevo siglo. En la mayoría de las agroindustrias optó por crear esquemas de gobernanza novedosos mediante entes con participación del sector privado y de los gobiernos nacional y/o provinciales. El objetivo fue que las estrategias de los agentes se explicitaran, enfrentaran y negociaran en un ámbito de origen estatal que se superponía, con mayor o menor poder, a las negociaciones entre privados que transcurren en los mercados. Para que estos espacios surgieran y funcionaran se delimitaron temas que podrían tratarse, excluyendo a veces las discusiones más importantes sobre precios al interior de las cadenas productivas, e incluyendo acciones en el que el nivel de tensiones era menor y aparentemente podrían beneficiar al conjunto de los actores, más referidas a una promoción entendida como mejora de la calidad o de la competitividad. El Estado aparece en estos espacios (como el FVM o la COVIAR) como creador, promotor, financiador, árbitro y/o una parte más, según el caso. El rol de fiscalizador del Estado legitimado en su poder de policía se conserva en otras instancias, como los organismos de control de cumplimiento de las normas de calidad, como el INV para la vitivinicultura.

El FVM y la COVIAR son lo que Mc Dermott, Corredoira y Burlot (2011) llaman Instituciones Público - Privadas (IPP), las cuales son creadas en función de proveer recursos colectivos y de difundir ampliamente sus logros que sirvan para la innovación, teniendo reglas de inclusión y gobernanza participativa de los actores públicos y privados relevantes. Su forma legal es "mixta", en tanto tienen participación y pueden acceder a financiamiento estatal y privado.

En otras agroindustrias se pueden mencionar algunos casos paradigmáticos de espacios de concertación que pueden ser comparados con los existentes en la vitivinicultura para ver similitudes y diferencias, y comprender su poder y sus límites.

En 2001 se creó el Instituto de Promoción de la Carne Vacuna Argentina (IPCVA), ente de derecho público no estatal, que funciona con fondos privados que aportan de manera conjunta productores ganaderos y frigoríficos de todo el país a través de una contribución obligatoria. Este Instituto se orienta a mejorar y consolidar la imagen de los productos cárnicos argentinos y su competitividad nacional e internacional. De la conducción participan el Estado, los productores y los industriales. El control de la calidad de los productos continúa como potestad del SENASA.

El sector yerbatero había perdido sus organismos estatales reguladores con el Decreto de Desregulación 2.284/1991. El poder de los hipermercados y la crisis del país impactaron sobre el gran número de pequeños productores. El Instituto Nacional de la Yerba Mate (INYM) se gestó en 2002, en el marco de una profunda crisis del sector. Se creó por ley nacional 25.564, como ente de derecho público no estatal. Sus objetivos son promover, fomentar y fortalecer el desarrollo de la producción, elaboración, industrialización, 
comercialización y consumo de la yerba mate y derivados procurando la sustentabilidad de los distintos sectores involucrados en la actividad. El directorio tiene representación del Poder Ejecutivo Nacional, los gobiernos provinciales de Corrientes y Misiones, el sector industrial, las cooperativas, los productores primarios, los secaderos y los trabajadores rurales. La financiación proviene de una tasa obligatoria de fiscalización (Instituto Nacional de la Yerba Mate, 2017).

El INYM realiza tres acciones principales: a) la fijación anual del precio de la materia prima, que debe decidirse en la mesa de directorio; b) la difusión del producto para incentivar su consumo; y c) el desarrollo del Programa Regional de Asistencia al sector yerbatero, que apunta a capacitar y asistir a todos los sectores involucrados en la actividad. Es decir, aquí un concepto amplio de promoción en sus dos vertientes. Las decisiones se toman por mayoría en el directorio salvo la determinación del precio de la yerba, que debe ser aprobada por unanimidad, y que en caso de no alcanzarse debe laudar la Secretaría de Agricultura de la Nación (Ramírez, 2013).

Regresando a la vitivinicultura, se puede observar que el modo en que entienden o asumen la COVIAR y el FVM la función de promoción se parece más al del IPCVA (es decir, no participan del control de la oferta ni de acuerdos de precios), y difiere por lo tanto del INYM (que propicia la concertación de valores de la materia prima).

Tras la crisis de la economía argentina en 2001 y las nuevas posibilidades de exportación que se abrieron tras la devaluación, la mayoría de las organizaciones de la vitivinicultura, bajo la convocatoria del INTA, confluyeron en la formulación del Plan Estratégico Vitivinícola Argentina 2020 (PEVI). La experiencia internacional de países como Australia, que ya tenían un plan de este tipo con resultados exitosos, se presentó como el ejemplo a seguir.

Los tres objetivos adoptados en el PEVI argentino fueron la inserción de los vinos varietales en los mercados del norte, el reimpulso del mercado argentino y latinoamericano, y la integración de los pequeños productores.

Para la implementación se creó por ley nacional 25.849/2003 la COVIAR, ente público no estatal que está conducido por un directorio conformado por entidades del sector privado en su mayoría, además de algunos gobiernos provinciales, el INTA y el INV (Moscheni \& Hernández, 2020).

El Directorio reedita, e incluso con mayor número de actores y representatividad, al antiguo directorio del Instituto del Vino, con poder de decisión sobre los objetivos de la Corporación.

Con la aparición de la Corporación Vitivinícola de Argentina (COVIAR)... el Estado Nacional descarga en la "iniciativa privada" (concentrada en sus agentes más encumbrados) el poder de decisión e innovación del circuito.

El principal objetivo de este nuevo actor de naturaleza privada-pública (en este orden) es reorientar la producción y adecuarla al seguimiento de las señales del mercado (García \& Lampreabe, 2009, p. 172).

La COVIAR es financiada directamente por el sector privado en parte y en parte por el Estado, quien consiguió un importante préstamo del Banco Interamericano de Desarrollo y asumió su devolución para financiar un proyecto destinado a productores y bodegas, denominado "Proviar". Mientras que el INV recibe fondos exclusivamente del presupuesto del Estado nacional -el cual en su gran mayoría surge también de impuestos cobrado a los privados-.

La COVIAR ha financiado programas de integración de productores mediante contratos de largo plazo con las bodegas, investigaciones en temas priorizados para mejorar la calidad de los vinos, estudios de mercados, propagandas en el país y en el extranjero para posicionar los vinos argentinos, asesoramiento a pequeños productores a través de Centros de Desarrollo Vitícola localizado en las sedes de INTA en departamentos con producción vitícola del país, etc. También ha influido sobre el gobierno nacional y los gobiernos provinciales para evitar la aplicación de nuevos impuestos, lograr la declaración del vino como bebida nacional, entre otras.

Como bien indica Chazarreta (2014), para los sectores de la burguesía vitivinícola nacional y en particular el sector cooperativo (la Asociación de Cooperativas Vitivinícola tiene un lugar importante en COVIAR y 
su actor central es Fecovita, que nuclea a las cooperativas mendocinas), este espacio de concertación permite posicionarse ante el Estado como un bloque con amplia representación.

Las decisiones que fue adoptando COVIAR a lo largo de los años motivaron que el Centro de Viñateros y Bodegueros del Este que tenía lugar en su Directorio decidiera dejar de participar de las reuniones. Más recientemente, Bodegas de Argentina expresó también su renuncia motivada por disidencias con otras organizaciones sobre el tratado de libre comercio de la Argentina y la Unión Europea, el último recambio de autoridades (fue elegido el líder de la Unión Vitivinícola Argentina, otra entidad bodeguera), el contenido que debería tener la actualización a 2030 del PEVI, el aumento de la contribución monetaria que deben pagar las industrias, etc.

Se demostró la diferencia entre el sector empresarial que elabora los mayores volúmenes y nuclea a las bodegas con capacidad para la exportación (y por lo tanto pagan las mayores contribuciones al plan) liderado por Bodegas de Argentina que demanda que la COVIAR se oriente a fortalecer la competitividad internacional especialmente de vinos finos, frente a otro grupo... cuyos afiliados tienen sus principales inversiones en el mercado interno.

Estas situaciones le han restado representatividad a COVIAR y han debilitado profundamente la hegemonía construida por el sector empresario, dejando de manifiesto la heterogeneidad de intereses (Moscheni \& Hernández, 2020, p. 22).

Es decir, las disputas entre las entidades que apoyan medidas proteccionistas del mercado interno frente a la importación y las que prefieren la apertura por su mayor capacidad para competir en mercados internacionales ha generado recientemente una escisión dentro de COVIAR, que es la misma que existió desde el origen en el FVM. Esto demuestra los distintos modelos de desarrollo de la vitivinicultura en pugna y que el sector bodeguero tiene disidencias a su interior que se suman a las pujas históricas de precios con los viñateros y los comercializadores.

Sumado a ello, durante 2021 se ha conformado una "Mesa Vitivinícola" integrada por Bodegas de Argentina, Cámara de Bodegueros de San Juan, Centro de Viñateros y Bodegueros del Esta de Mendoza, Federación de Viñateros de San Juan, Asociación de Viñateros Independientes de San Juan, Asociación Vitivinícola del Valle Calchaquí de Salta y Asociación de Productores del Este de Mendoza. Esta entidad, que todavía no tiene personería jurídica, involucra los grandes elaboradores del país y a los más pequeños productores, de manera que el conflicto de intereses es latente y su surgimiento está más vinculado a constituirse en alternativa frente a la Corporación que a su posibilidad efectiva de consolidarse en la asunción de tareas de promoción.

El concepto de promoción que entre 1960 y 1990 generó amplias críticas al INV en su ejercicio para regular la oferta, también en el nuevo siglo lo provoca en su implementación de la manera que lo hace la COVIAR, incluso cuando ella lo entiende solo como apoyo al crecimiento económico y competitivo de los actores.

Desde 2019 se inició el proceso de renovación del PEVI vitivinícola, dado el cumplimiento del plazo para el cual fue creado. El proceso fue liderado por un equipo técnico del INTA que propició instancias de amplia participación provincial y por cadenas productivas de base vitícola. La versión final fue publicada a principios de 2021. La actitud de las entidades que no están dentro de COVIAR ha sido de rechazo a todo el proceso, más allá del contenido final que adoptó el Plan. Los gobiernos provinciales, el INV y el gobierno nacional, en cambio, lo han apoyado argumentando sobre la necesidad de que exista este espacio de concertación en la vitivinicultura para que asuma estas tareas de promoción que no pueden quedar a cargo o bajo a la iniciativa de empresas individuales.

El nuevo PEVI plantea objetivos amplios de sustentabilidad económica, social y ambiental en la vitivinicultura, ampliando los horizontes y desafíos para la concertación en la cadena productiva.

\section{LA RELACIÓN ENTRE LAS INSTITUCIONES}

La función de promoción concentrada en el INV y entendida como regulación de mercados y generación de incentivos a la producción y diversificación pasó a estar distribuida principalmente, desde la década de 
1990, entre los gobiernos provinciales cuyanos que tomaron ambas tareas y dos entes con participación estatal y privada.

El INV forma parte de la COVIAR como un actor más. En su origen fue un activo participante en su gestación. Existe una distribución de funciones entre los organismos y cierto consenso entre ambos acerca de respetar la existencia del otro, tal como sostuvo uno de los entrevistados: "En COVIAR hay quejas respecto al INV a que presiona mucho, que es costoso, porque tiene una estructura... pero nadie de esta mesa nadie ha planteado nunca la desaparición del INV" (Dirigente de COVIAR, entrevista personal, 20/9/2018).

La delimitación de funciones aparenta estar clara en el siglo XXI. El INV se encarga de la creación de normas de calidad y de la fiscalización de su cumplimiento, de las estadísticas y de la representación internacional; la COVIAR y el FVM asumen la promoción, entendida como publicidad y desarrollo de los actores; mientras que los gobiernos provinciales (principalmente) y el nacional conservan el poder coercitivo para intervenir en los mercados a través del establecimiento de un cupo para mostos u otras acciones como créditos subsidiados, financiación de investigaciones, innovaciones tecnológicas, propagandas, etc., ejerciendo estos últimos tanto la primera como la segunda acepción del concepto de promoción, según el sentido que le dio la antigua Ley General de Vinos.

Ahora bien, la superposición existe en algunos temas:

- Investigación: el INV, la COVIAR y también el INTA tienen sus programas.

- La publicidad: COVIAR, los gobiernos provinciales y el FVM realizan acciones (a veces en conjunto) e, incluso, el INV se involucró también en la promoción del vino turista y el envase bag in box en la primera parte de la década de 2010, aunque por un periodo breve, porque luego de 2015 el nuevo presidente decidió que esas tareas no correspondían a esta organización. A esto también hay que sumarle las campañas de Wofa en el exterior.

- En la participación en la regulación de la oferta: porque las medidas aparentemente técnicas del INV influyen indirectamente en ella (por ejemplo, los pronósticos de cosecha o la fecha de liberación de vinos), la decisión de COVIAR acerca de qué productos promover o qué actores financiar tiene consecuencias y los gobiernos provinciales despliegan políticas que los hacen participar de diferentes modos en los mercados (como el cupo de mostos).

Además, si la COVIAR manifiesta posición sobre las normativas vitivinícolas (como suele ocurrir cuando desde su seno se pide la adaptación de normas para facilitar la elaboración de vinos o su inserción en el comercio internacional), ${ }^{9}$ las acciones se cruzan asiduamente y la delimitación ya no es precisa, sino que es más bien semejante a una compleja red donde los diferentes actores despliegan sus estrategias y buscan mediante sus líderes que el poder del Estado, de las entidades mixtas y los fondos disponibles se orienten en función de sus intereses particulares.

La red o arena de instituciones se completó con el accionar de otras organizaciones como Pro Mendoza, el Instituto de Desarrollo Rural de esa provincia o algunas acciones de las mismas cámaras de empresarios. Algunos autores como Mc Dermott, Corredoira y Burlot (2011) o Richardo-Jorba (2008) consideran que estas entidades han tenidos resultados positivos en términos de difusión de las innovaciones en la cadena productiva, de aumento de las exportaciones, entre otras, etc. Sin embargo, no han eliminado la conflictividad entre los actores ni han detenido el proceso de expulsión de pequeños productores de los mercados.

\section{CONCLUSIONES}

El artículo ha recorrido la trayectoria de la definición y la concreción del concepto promoción de la vitivinicultura nacional en las últimas 6 décadas. La concepción acuñada por la Ley General de Vinos fue amplia porque permitió tanto el apoyo a la competitividad como la regulación de la oferta, bajo el argumento 
que ambas promovían la subsistencia o crecimiento de los actores. Ellas se concretaron en tareas cuyos resultados redistribuyeron poder y recursos.

La promoción estatal de la vitivinicultura aparenta ser necesaria, en beneficio del interés general, y las decisiones en ese sentido intentaron aparecer como resultado de la voluntad general a lo largo de las últimas 6 décadas. Ahora bien, la extensión del concepto a la regulación de la oferta en los mercados para garantizar precios a algunos actores en detrimento de otros demostró que las acciones del Estado no son neutrales ni en sus resultados ni en su diseño.

La redefinición del concepto en la década de 1990 en el seno del INV, la dispersión de responsabilidades entre diversas organizaciones y la mayor participación privada en la financiación y en la toma de decisiones dentro del FVM y la COVIAR, obedecieron a un modelo neoliberal del Estado que comenzó a fines del siglo XX y se modificó solo en parte en el siglo XXI.

La asunción de tareas de promoción por parte del Estado es una práctica constitutiva del Estado capitalista en múltiples actividades producivas. En la vitivinicultura argentina puede rastrearse desde los orígenes de la actividad y se potencia en el periodo abordado en este trabajo.

La redefinición de las funciones estatales y de sus límites con la sociedad, siguiendo los postulados de Jessop, encuentra en estos años en la vitivinicultura nacional experiencias diversas, que estuvieron influidas por los cambios en la política económica nacional y en las estrategias de los agentes para lograr influencia sobre las decisiones adoptadas por organismos donde ejercían el poder únicamente los gobiernos o espacios de concertación con mayoría del sector privado.

La función de promoción es un concepto polisémico y no neutral, que entraña la generación de externalidades positivas que pueden ser apropiadas por unos más que por otros, dependiendo de los recursos previos y del éxito de sus estrategias. Las políticas públicas, aunque intenten aparentar que contribuyen al bien de todos, implican asignación de fondos que podrían tener otros fines y la orientación de un aparato productivo según modelos de desarrollo definidos en el que algunos agentes tendrán mejores posibilidades que otros.

El desarrollo de la calidad, competitividad, productos y mercados de una agroindustria en una economía capitalista de un país subdesarrollado depende, en el caso en estudio, de las acciones del Estado, en las cuales pueden tener diferentes grados de participación los agentes del sector privado que son beneficiados o perjudicados por ellas. Esa participación es variable con el tiempo, generalmente se lleva a la práctica a través de organizaciones (cámaras, federaciones, etc.) y se dota de legitimidad a través de espacios de concertación.

\section{BibLIOGRAFÍA}

Azpiazu, D., \& Basualdo, E. (2001). El complejo vitivinicola argentino en los noventa: potencialidades y restricciones. Buenos Aires: FLACSO

Azpiazu, D., \& Basualdo, E. (2003). Estudios sectoriales. Componente: Industria Vitivinicola. Buenos Aires: CEPALONU

Barrio, P. (2008). El empresariado vitivinícola de la provincia de Mendoza (Argentina) a principios del siglo XX. Historia Agraria (45), 81-111

Bertranou, J. (2011). Estado y agencias público-privadas en la promoción del desarrollo productivo en la provincia de Mendoza. Documentos y aportes en administración pública y gestión estatal, 11(17), 7-40

Bocco, A. (2007). Transformaciones sociales y espaciales en la vitivinicultura mendocina. Buenos Aires. En M. y. Radonich, Reestructuraciones sociales en cadenas agroalimentarias (pp. 11-143). Mendoza: Editorial La Colmena

Borcosque, L. A. (2006). Crisis, productores y Estado en la vitivinicultura sanjuanina (1930-1943). La Universidad, $3(25)$ 
Bouret Vespa, D. (2015). Moral y salud en el consumo de vinos. Una perspectiva histórica de las variables que inciden en el consumo de vinos y la conformación del gusto en los sectores urbanos durante la modernización. Montevideo: Universidad de la República de Uruguay

Bragoni, B., Mateu, A., Mellado, V., \& Olguín, P. (2008). Siguiendo los pasos de la Crisis: origen y conformación de las entidades empresarias vitivinícolas. XXI Jornadas de Historia Económica. Buenos Aires: Universidad Nacional de Tres de Febrero

Carrizo, C., \& Moscheni, M. (2013). Organizaciones, poder y grupos hegemónicos. Entre Ríos: XI Congreso Nacional de Ciencia Política de la Sociedad Argentina de Análisis Políticos

Castiñeira de Dios, E. (1999). Régimen legal de la vitivinicultura. Buenos Aires: Sociedad Anónima Editora, Comercial, Industrial y Financiera

Cernadas, J., \& Forcinito, K. (2004). Aportes para una caracterización económica del complejo vitivinícola de Cuyo (Argentina) en la etapa inicial de la reestructuración liberal, 1976 - 1989. II Congreso de Historia Económica de la Asociación Mexicana de Historia Económica. México D.F.

Chazarreta, A. (2013). Capital extranjero y agroindustria. Notas para una discusión sobre los cambios en la burguesía vitivinícola de Argentina a partir de la década del '90. Mundo Agrario, 23(26)

Chazarreta, A. (2014). Los cambios en la organización gremial de la burguesía vitivinícola de la provincia de Mendoza, Argentina (1990-2011). Pampa, 10, 55-85.

Chazarreta, A. (2019). Transformaciones recientes de la actividad vitivinícola argentina y avance del agronegocio, 1990 - 2010. Revista Latinoamericana de Estudios Rurales, 4(7)

COVIAR. (2020). Actualización Plan Estratégico Argentina Vitivinicola 2020 con horizonte al 2030

Day, J. (2013). Una Argentina competitiva, productiva y federal. Actualidad y desafíos en la cadena vitivinícola argentina. Documento de Trabajo IERAL Fundación Mediterránea, 19(124)

De La Torre, D. (2011). Estado, Sociedad y Economía en la provincia de San Juan 1950 - 1976. San Juan: Fundación Universidad Nacional de San Juan

De La Torre, D. (2017). Estado, economía y sociedad en la provincia de San Juan. Periodo 1976 - 1989. San Juan: UNSJ

Decreto del Poder Ejecutivo Nacional de la República Argentina No 1279/2003. Instituto Nacional de Vitivinicultura Estructura organizativa primer nivel de conducción. Fecha de publicación: 26 de mayo de 2003

Díaz Araujo, E., \& Iuvaro, M. J. (2006). Vitivinicultura y Derecho. Buenos Aires: Duken

Dulcich, F. (2016). Reestructuración productiva en un contexto de apertura y desregulación: la industria vitivinícola argentina ante los desafíos de la reducción de escala.H-industri@, 10(18),79-105

Ferreyra, M. (2010). Expansión y retracción de circuitos productivos en el marco de distintos modos de regulación económica. Un estudio comparado de las causas que generan las fases de su expansión y retracción. El circuito vitivinicola y el hidrocarburifero en Mendoza (Tesis doctoral). Buenos Aires: FLACSO

Ferreyra, M. (2012). El cambio en los valores relativos de los precios en la cadena de valor del vino argentino. Revista Eletrônica AGB-TL, 1(16), 10-42

Ferreyra, M., \& Jofré, J. L. (2013). La génesis institucional de las regulaciones económicas en la industria del vino en Mendoza, Argentina (1977-1980). Revista de Historia de América, 148, 107-133

Fili, J., \& Hernández, J. (2018). Crisis vitivinícola de los 80 en Argentina. RIVAR Revista Iberoamericana de Vitivicultura, Agroindustria y Ruralidad, 4(13), 98-116

García, L., \& Lampreabe, F. (2009). Heterogeneidad y poder en las políticas públicas regionales: Las experiencias de los circuitos del tabaco, la vid y el algodón. Revista de estudios regionales y mercados de trabajo, 5, 153-176

Hernández,J.J. (2014a). El Instituto Nacional de Vitivinicultura: el regulador creado, intervenido y reformado. Revista Posdata: revista de reflexión y análisis politico, 19(1), 71- 103

Hernández, J. J. (2014b). La ley 23.149 de fraccionamiento en origen en Argentina: su proceso de surgimiento, los problemas para su implementación y sus resultados. Revista H-industria@, Revista de historia de la industria, los servicios y las empresas en América Latina, 8(15), 56-85 
Hernández, J.J. (2017a). El Instituto Nacional de Vitivinicultura en el periodo 1976-1989: sus políticas y los conflictos por el acceso a sus cargos directivos. En D. De La Torre, Estado, economía y sociedad en la provincia de San Juan. Periodo 1976 - 1989 (pp. 193-211). San Juan: UNSJ

Hernández, J. J. (2017b). La CAVIC en la vitivinicultura de San Juan. Política pública y redistribución en disputa. En M. M. Patrouilleau, W. Mioni, \& C. Aranguren, Politicas públicas en la ruralidad argentina (pp. 145-160). Buenos Aires: Ediciones INTA

Hernandez, J. J. (2020). El Instituto Nacional de Vitivinicultura (1959-2015). Estado, estrategias y regulación (Tesis doctoral). Mendoza: UNCUYO

Hernandez, J. J., \& Doncel Ramallo, L. (2020). El concepto forma de Estado. Desde la Teoría de la Regulación parisina a la contribución de Jessop. Revista Estudios Sociales Contemporáneos, 23, 203-216

Hernández, J. J., Novello, J. R., Parera, C., Perez Peña, J., Diaz Bruno, A., Santi, C. y Battistella, M. (2020). Los planes estratégicos vitivinícolas: estudio comparativo. Realidad Económica, 50(335), 101-130

Instituto Nacional de la Yerba Mate. (2017). Sitio web oficial del Instituto Nacional de la Yerba Mate. Recuperado el 1 de agosto de 2017 de http://www.inym.org.ar/publico/el-inym/historia/

Ley de la República Argentina No 14.878/1959. Ley General de Vinos. Fecha de publicación: 6 de noviembre de 1959. Jessop, R. (2008). El futuro del Estado capitalista. Madrid: Los libros de la Catarata.

Jessop, R. (2014). El Estado y el poder. Utopia y praxis latinoamericana. Revista Internacional de filosofía iberoamericana y teoría socialL, 19(66), 19-35

Mateu, A. M., \& Stein, S. (2008). El vino y sus revoluciones. Una antología histórica sobre el desarrollo de la industria vitivinicola argentina. Mendoza: EDIUNC

Mateu, A., \& Iriart Gabrielli, G. (2018a). ¿Intervencionismo estatal o liberalismo en la vitivinicultura de Mendoza de entreguerras? Leopoldo Suarez y Francisco Trianes, expertos y militantes lencinistas. RIVAR Revista Iberoamericana de Vitivicultura, Agroindustria y Ruralidad, 4(13), 8-32

Mateu, A., \& Iriart Gabrielli, G. (2018b). "La primera condición del vino es que sea vino". Los antecedentes de la creación del Instituto Nacional de Vitivinicultura (1959). Travesía, Suplemento Electrónico, VII Reunión del Comité Académico "Historia, regiones y fronteras", 2, 217-241

Mateu, A., \& Natali, P. (2011). Políticas públicas, corporaciones y reconversión vitivinícola: ¿encuentro o desencuentro? En Primer Congreso Chileno de Historia Económica. Santiago de Chile: Universidad Andrés Bello

Mc Dermott, G., Corredoira, R \& Burlot, G. (2011) Los racimos de la innovación. Cuyo a la vanguardia vitivinicola: Nuevas herramientas poara aumentar la competitividad. Mendoza: UNCUYO

Mellado, M. V., \& Olguín, P. (2007). Industria vitivinícola, crisis y fracaso empresario. Un estudio comparado del grupo Greco y de Bodegas y Viñedos Giol. En 1 Congreso Latinoamericano de Historia Económica-4 Jornadas Uruguayas de Historia Económica. Montevideo: Universidad de la República

Moscheni, M. (2013). Acumulación, reproducción y conflicto. El circuito productivo de la vitivinicultura sanjuanina (Tesis doctoral). Mendoza: Tesis doctoral. Universidad Nacional de Cuyo

Moscheni, M., \& Hernández, J. J. (2020). Vinos, actores y tramas: espacios de concertación de políticas en la vitivinicultura argentina. Revista Internacional de Organizaciones, 24

Ramírez, D. (2013). La acción del Estado en una economía regional desplazada. Acerca de procesos y conflictos en el complejo de la yerba mate. En C. Gras, \& V. Hernández, El agro como negocio. Producción, sociedad y territorios en la globalización (pp. 171-191). Buenos

Richardo-Jorba, R. (2008). Los empresarios y la construccion de la vitivinicultura capitalista en la provincia de mendoza (argentina), 1850-2006. Revista Electrónica De Geografía Y Ciencias Sociales, 12(271). Universidad de Barcelona

Román, J. (2018). Política, corporaciones y trayectoria organizacional de pequeños productores y bodegueros en la zona este de Mendoza, Argentina (1980-2017). RIVAR Revista Iberoamericana de Vitivicultura, Agroindustria y Ruralidad, 4(13), 141-157 
Semienchuk, L. (2015). Ley de Reconversión Vitivinícola № 22667: su discusión durante la gran crisis vitivinícola en la década de 1980. En V Jornadas de Becarios y Tesistas del Departamento de Ciencias Sociales. Buenos Aires: Universidad Nacional de Quilmes

Valenzuela Espinoza, I. (2014). El enfoque estratégico-relacional: implicancias para el estudio del Estado, las instituciones y el desarrollo en América Latina. Revista de Ciencias Sociales, 33, 7-31

\section{Notas}

1 Las entrevistas han servido para el análisis de la bibliografía y de los diarios y para la comprensión del proceso histórico. Se relata la cita de una de ellas, se referencia a otras y se mencionan todas al final. Las entrevistas fueron hechas como una parte de una investigación mayor sobre la historia del INV en el marco de la tesis doctoral "El Instituto Nacional de Vitivinicultura (1959 - 2015). Estado, estrategias y regulación" de Hernández (2020), Universidad Nacional de Cuyo.

2 Algunos autores/as que han hecho contribuciones a la temática a la que se refiere este artículo con distintos enfoques son Borcosque (2006), Mateu y Stein (2008) y Mateu e Iriart Gabrielli (2018a y 2018b), Cernadas y Forcinito (2004), De La Torre (2011 y 2017), Semienchuk (2015), Ferreyra y Jofré (2013), Mellado y Olguín (2007); Bragoni, Mateu, Mellado y Olguín (2008), Mateu y Natali (2011), Azpiazu y Basualdo (2001 y 2003), Bocco (2007), Chazarreta (2013 y 2019), Díaz Araujo e Iuvaro (2006); Dulcich (2016), Moscheni (2013); Bertranou (2011), etc.

3 Un estudio completo de estas asimetrías y de la crisis de la vitivinicultura argentina en la década de 1980 se puede leer en Semienchuk (2015) y Fili y Hernández (2018).

4 Díaz Araujo e Iuvaro (2006, pp. 46-54) enumeran algunas de las formas de intervención que el Estado puede ejercer en la vitivinicultura ante las crisis:

a) sobre la producción: bloqueos parciales o prorrateos para programación de ventas y compra, derivación a destilación, destrucción o derrame de excedentes;

b) sobre las plantaciones: prohibición de plantar, control de rendimientos, asignación de superficies y erradicación de viñedos;

c) sobre los precios: fijación de precios mínimos y sistema de precios de paridad o garantizados;

d) sobre el comercio exterior: limitaciones a las importaciones y fomento a las exportaciones;

e) sobre la demanda: promoción del consumo.

5 Para un estudio comparativo de los planes estratégicos vitivinícolas de los países, se puede consultar Hernández y otros (2020).

6 Castiñeira de Dios (1999) menciona 4 leyes nacionales precedentes que marcan el desarrollo de la legislación nacional vitivinícola, Mateu e Iriart Gabrielli (2018b) hace lo mismo para Mendoza. Hernández (2014a) analiza el proceso de surgimiento de la ley $14.878 / 1959$, cuyo valor es que no solo brinda normas de calidad, sino que también crea un organismo regulador autónomo.

7 Una explicación completa de la historia del INV y de sus acciones se puede leer en Hernández (2020).

8 Para un estudio completo de la trayectoria de Giol y CAVIC se pueden leer, por ejemplo, los textos de Bragoni, Mateu, Mellado y Olguín (2008), Mellado y Olguín (2007) y Hernández (2017b).

9 Un ejemplo de la influencia de COVIAR en el cambio de las disposiciones de control de calidad fue la Resolución 44/2015, que estableció que el INV controlaría las bebidas artificiales a base de vino que no estaban definidas en el artículo 17 de la Ley 14.878/1959 y sus modificatorias. La norma llegó tras la solicitud formal de COVIAR. 